\title{
¿Crisis del presidencialismo o crisis de la presidencia? El liderazgo presidencial de Sebastián Piñera ${ }^{1}$
}

\section{Crisis of presidentialism or crisis of the presidency? The presidential leadership of Sebastián Piñera}

\author{
Carlos Huneeus Madge ${ }^{2}$ \\ Universidad de Chile, Chile \\ Mariana Pastén Guzmán ${ }^{3}$ \\ Universidad Alberto Hurtado, Chile
}

\begin{abstract}
"Le he señalado a Sebastián (Piñera), en más de una oportunidad, que no se puede ser protagonista de la política y simultáneamente activista de los negocios. Aquí hay que escoger: el que entre en la política abandona los negocios; Y el que está en los negocios, debe abandonar la política”"
\end{abstract}

\begin{abstract}
RESUMEN El presente artículo analiza el liderazgo del Presidente Sebastián Piñera a lo largo del "estallido social" y sus consecuencias en el proceso político durante su segundo gobierno. La tesis guía es que el liderazgo presidencial es una variable indispensable para comprender el presidencialismo y la presidencia, en este caso de Sebastián Piñera. Nuestro punto de partida es que Piñera posee un liderazgo pobre según la definición de $\mathrm{Helms}^{5}$, al no reunir las habilidades requeridas para ser un presidente efectivo, especialmente en su débil
\end{abstract}

1. Agradecemos los comentarios de los evaluadores de la primera versión, del editor del área de ciencia política de la revista, de Carlos Tromben y Rodrigo Cuevas.

2. Carlos Huneeus Madge es Doctor en Ciencia Política de la Universidad de Heidelberg (Alemania). Actualmente se desempeña como académico de Ciencia Política en la Universidad de Chile (Chile). Mail: chuneeus@derecho.uchile.cl

3. Mariana Pastén Guzmán es Cientista Política de la Universidad Alberto Hurtado (Chile). Actualmente se desempeña como ayudante de investigación del profesor Carlos Huneeus. Mail: mariana. pastenguzman@gmail.com

4. Citado por DAZA y DEL SOLAR (2017) p. 221.

5. HELMS (2012). 
inteligencia emocional, que llegó a ser una discapacidad emocional de acuerdo a la definición de Greenstein ${ }^{6}$. Estas debilidades del liderazgo están influidas por su experiencia como hombre de negocios y su inexperiencia política.

PALABRAS CLAVE Liderazgo; presidencialismo; presidencia; crisis.

ABSTRACT This article analyzes the leadership of President Sebastián Piñera throughout the "social outbreak", and its consequences for the political process during his second government. The guiding thesis is that presidential leadership is a crucial variable for an understanding of presidentialism and the presidency, in this case of Sebastián Piñera. Our starting point is that Piñera's leadership is poor according to the definition of Helms (2012), since he does not have the skills required to be an effective president; this is especially the case of his weak emotional intelligence, which is an emotional disability according to the definition of Greenstein (200o). These leadership weaknesses are influenced by his experience as a businessman and his political inexperience.

KEYWORDS Woman; Leadership; presidentialism; presidency; crisis.

\section{El problema}

Los cambios en los regímenes políticos son gatillados por hechos puntuales, que actúan como precipitantes de carencias y limitaciones del sistema político. Bajo una aparente normalidad, un conflicto latente en la sociedad, no percibido por los gobernantes, sorpresivamente se transforma en un conflicto sistémico por el impacto de un hecho puntual. El aumento de la tarifa del Metro fue el precipitante de la protesta social ${ }^{7}$, que remeció al país y paralizó al Gobierno.

Desde el 18 de octubre de 2019 ("el 18-O", "el estallido social", como se le conoce) se produjo una protesta social inédita en su magnitud y alcances políticos, sin que ningún partido la hubiese convocado ${ }^{8}$. Los manifestantes protestaron por los altos costos de la educación y los servicios de salud, las bajas pensiones que entregaban las AFP, exigiendo su fin ("No + AFP"), los abusos de casas comerciales (La Polar) y la colusión de precios por varias empresas (farmacias, pollos, papel higiénico y pañales, el conforgate). También había malestar hacia empresas que proveían bienes públicos (sanitarias y electricidad) que tuvieron fallas en el servicio que perjudicaron a decenas de miles de hogares. En la práctica, cada hogar se vio perjudicado por alguno de estos abusos.

6. GREENSTEIN (2000).

7. Empleamos el concepto precipitante en la definición de MAC-IVER (1948).

8. Sobre el estallido social, véase AVENDAÑO y ESCUDERO (2020); HUNEEUS (2020). 
El 25 de octubre más de un millón de personas se congregaron en Santiago, la mayor manifestación desde la campaña del No en el plebiscito de 1988, que gatilló el fin del régimen de Pinochet. Los manifestantes no portaron banderas de los partidos de oposición; tampoco participaron dirigentes o parlamentarios. La manifestación mostró a los chilenos y al mundo cuán alejados están los partidos de la ciudadanía y cuán complejo sería cerrar esa gran brecha.

También sorprendió la violencia empleada por grupos minoritarios contra bienes públicos y privados, destruyendo entre el 19 de octubre y el 27 de noviembre 67 estaciones del Metro y que en los días siguientes saquearon o incendiaron decenas de supermercados y locales comerciales, la mayoría de ellos en la periferia de la capital ${ }^{9}$. Estas acciones desbordaron la acción de Carabineros ${ }^{10}$, cuyos efectivos actuaron con extrema violencia, con graves atropellos a los derechos humanos. Estos fueron condenados por los principales organismos internacionales de defensa de los derechos humanos, los mismos que décadas atrás condenaron a la dictadura ${ }^{11}$.

El estallido social fue de la mayor importancia porque fue una coyuntura crítica ${ }^{12}$, que produjo importantes cambios en el sistema político. Fue provocado por legados de la dictadura de Pinochet, destacando la Constitución de 1980, redactada siguiendo el modelo de una democracia protegida y autoritaria, con tutela militar y pluralismo político limitado ${ }^{13}$. En segundo lugar, por singularidades del cambio de régimen -por la reforma en el procedimiento, sin ruptura en el contenido democrático ${ }^{14}$-, con importantes continuidades, destacando la permanencia del general Pinochet como comandante en jefe del Ejército durante ocho años, el sistema económico que es de economía de mercado puro de acuerdo a la tipología de Linz y Stepan ${ }^{15}$, que es incompatible con una democracia moderna. En tercer lugar, por decisiones de los nuevos gobernantes, entre las cuales destaca haber optado más por la continuidad que por la

9. https://ddhh.minjusticia.gob.cl/media/2019/10/30-11-19.pdf.

10. Carabineros estaba sacudido por casos de corrupción que involucraban a varios oficiales superiores, graves atropellos a los derechos humanos ante el conflicto en La Araucanía que terminaron con la muerte de comuneros mapuches (caso Catrillanca) y acusaciones de obstrucción a la justicia. Para enfrentar esta crisis, el presidente llamó a retiro a dos cuerpos de generales en el plazo de un año, siendo sustituidos por coroneles que no tenían experiencia de mando y, por ello, baja confianza en los suboficiales. Por otro lado, Piñera tuvo cuatro ministros del Interior en cuatro años.

11. Una cronología de las primeras tres semanas de estallido social se encuentra en https://www. emol.com/noticias/Nacional/2019/11/08/966621/Cronologia-Tres-semanas-crisis-Chile.html.

12. COLLIER y COLLIER (1991).

13. HUNEEUS (2016).

14. Usamos los conceptos empleados para analizar la transición a la democracia en España, HUNEEUS (1985).

15. LINZ y STEPAN (1996). 
reforma del sistema económico y haber descuidado a los partidos. Esta continuidad y algunas decisiones de los gobiernos democráticos, dieron origen a una democracia con adjetivo, una democracia semisoberana ${ }^{16}$.

Estos legados condujeron a una crisis de legitimidad del sistema económico, sin haberse legitimado por su desempeño, con los buenos resultados macroeconómicos y la reducción de la pobreza ${ }^{17}$. A ello se suma una crisis de representación del sistema político, con baja participación electoral (49,1\% votó en la segunda vuelta de las elecciones presidenciales de 2017); escasa confianza en las instituciones (la confianza en los partidos es de un dígito desde hace años) y las elites políticas, especialmente los parlamentarios; y el debilitamiento de los partidos y la fragmentación del sistema de partidos, especialmente en la izquierda ${ }^{18}$.

La coyuntura crítica produjo legados que tendrán efectos duraderos. Habrá una nueva Constitución, que surgirá del proceso constituyente convocado por el Acuerdo por la Paz y la Nueva Constitución del 15 de noviembre de 2019 suscrito entre los partidos de gobierno y de la oposición ${ }^{19}$, el cual dio un cauce institucional al conflicto social. La nueva Constitución representa un cambio de vastos alcances ya que significará poner fin a la Constitución de 1980, el más importante legado de la dictadura de Pinochet.

La nueva Constitución fue una antigua demanda de la oposición, fue rechazada por la Unión Demócrata Independiente (UDI) y las organizaciones empresariales, mientras Renovación Nacional (RN) estuvo abierto a aceptar a poner fin a la Constitución de $1980^{20}$. El programa del gobierno de Sebastián Piñera no consideró una nueva Constitución, sino reformas a la de $1980^{21}$.

Este artículo analiza el liderazgo del Presidente Sebastián Piñera durante el "estallido social" y sus consecuencias en el proceso político ${ }^{22}$. Piñera fue el primer presidente de derecha que llegaba a La Moneda por elecciones libres desde Jorge Alessandri en

\section{HUNEEUS (2014).}

17. FFRENCH-DAVIS (2018).

18. CASTIGLIONI y ROVIRA-KALTWASSER (2016); LUNA (2017); HUNEEUS y AVENDAÑO (2018).

19. No fue suscrito por el Partido Comunista (PC) y algunos partidos del Frente Amplio.

20. La UDI se opuso hasta el final al Acuerdo, cediendo porque los otros partidos de Chile Vamos, RN y EVÓPOLI, aceptaron la nueva Constitución. https://www.elmostrador.cl/destacado/2019/11/09/ la-udi-se-resigna-a-un-cambio-constitucional-estamos-disponibles-para-las-reformas-que-seannecesarias/.

21. El gobierno reafirmó este planteamiento desde el primer día. https://www.icare.cl/contenidodigital/no-queremos-avance-proyecto-nueva-constitucion-bachelet-andres-chadwick-ministrodel-interior/.

22. DAZA y DEL SOLAR (2017) han escrito una interesante biografía de Piñera. Su trayectoria como hombre de negocios ha sido cuidadosamente investigada por JARA ROMÁN (2018); GUZMÁN y ROJAS (2017); TROMBEN (2016). 
1958. Fue el presidente con menor experiencia política que ha tenido Chile y enfrentó la más grave crisis política en los últimos 30 años y la pandemia del COVID-19, que provocó una crisis sanitaria y una severa crisis económica.

La tesis que guía el artículo es que el liderazgo presidencial es una importante variable independiente para comprender al presidencialismo y la presidencia de Sebastián Piñera, en particular. Nuestro punto de partida es que Piñera ha tenido un pobre liderazgo, en la definición de $\mathrm{Helms}^{23}$ por no reunir las habilidades requeridas para ser un presidente efectivo, especialmente su débil inteligencia emocional, que llegó a ser una discapacidad emocional de acuerdo a la definición de Greenstein ${ }^{24}$. Estas debilidades del liderazgo están influidas por su experiencia como hombre de negocios. Las habilidades que tuvo para tener éxito en los negocios no le favorecieron en política para tener un liderazgo presidencial efectivo. A esto se agrega su inexperiencia política.

El liderazgo presidencial es puesto a prueba en momentos de convulsión social e inestabilidad política. Son oportunidades en las cuales el presidente debe mostrar sus habilidades de jefe de Estado, jefe de gobierno y líder de la coalición que le apoya y adoptar las decisiones para enfrentar la crisis y salir de ella.

Las excepcionales condiciones que impone una crisis, con una alta centralización decisoria en el presidente y una drástica reducción de las opciones para salir de ella, entrega al liderazgo presidencial una función determinante para resolverla. Los presidentes disponen de similares recursos institucionales de autoridad, con los cuales consiguen diferentes resultados durante su gobierno y ello tiene bastante que ver con su estilo de liderazgo. Si bien es cierto las instituciones del presidencialismo son relativamente similares, hay distintas presidencias según el estilo de liderazgo de cada mandatario.

Durante el estallido social, el Presidente Sebastián Piñera (que había estado antes en La Moneda, 2010-2014) tuvo un mal desempeño (poor leadership) en la definición de $\mathrm{Helms}^{25}$, que lo define como un liderazgo inefectivo, que perjudica la gobernanza y daña al sistema político. El 18-O se mantuvo en La Moneda, sin tomar decisiones. Estaba convencido que la difícil situación social se calmaría con el correr de las horas. Por la noche, se ausentó de La Moneda por un breve tiempo para concurrir a una cena familiar en una pizzería de una comuna acomodada de Santiago. No apreció la naturaleza y gravedad del estallido social, desconoció las demandas ciudadanas e ignoró el malestar que había en la sociedad. Peor aún, no supo qué hacer.

23. HELMS (2012).

24. GREENSTEIN (2000).

25. HELMS (2012). 
Su desempeño como presidente suscitó, por primera vez en los últimos 30 años, el temor de que su continuidad en la presidencia agravaría la crisis y se puso en duda que pudiera terminar su mandato en marzo de $2022^{26}$. No se temía que fuera alejado de la presidencia por los militares, sino que por la presión de la ciudadanía, como le ocurrió al presidente de Argentina, Fernando de la Rúa, en diciembre de $200 \mathbf{1}^{27}$.

El liderazgo del Presidente Piñera perjudicó al país pues la pandemia del COVID-19 fue enfrentada con menos recursos políticos. La sociedad estaba dividida por las distintas posiciones ante el estallido social, el gobierno contaba con una bajísima aprobación ciudadana y su popularidad se había desplomado, alcanzando un $6 \%$ en noviembre 2019. En esas condiciones, la autoridad sanitaria tuvo limitaciones para persuadir a la ciudadanía a seguir sus recomendaciones de autocontrol. No escuchó las opiniones de los expertos, especialmente el Colegio Médico, y tomó decisiones erradas, promoviendo el "plan de retorno seguro" el 24 de abril de 2020 para iniciar el restablecimiento de la actividad económica, sin considerar las estadísticas del alto número de contagiados. En escasas semanas, Chile llegó a ser uno de los tres países en el mundo con el mayor número de contagiados y fallecidos por millón de habitantes ${ }^{28}$.

La investigación que apoya el artículo se basa en diversas fuentes, que incluyen la revisión de la prensa (escrita y digital), sus numerosos discursos mediante un análisis de contenido de carácter cualitativo y sus entrevistas de prensa. Además, hemos realizado entrevistas a senadores y diputados actualmente en ejercicio, a ex senadores, que le acompañaron en el Senado, a altos funcionarios del Ministerio Secretaría General de la Presidencia (SEGPRES) de esos años y a dirigentes y simpatizantes de RN, el partido del presidente. También hemos hecho un seguimiento de su desempeño durante la pandemia que permite comparar su estilo de liderazgo con el analizado durante el estallido social.

\section{El liderazgo presidencial}

Sabemos bastante del presidencialismo, pero poco de los presidentes. El conocimiento de la arquitectura institucional del presidencialismo no es suficiente para identificar sus capacidades y limitaciones. Ello significaría incurrir en una explicación mo-

26. En su primera entrevista de prensa que concedió el Presidente Piñera después del 18-O la periodista de la $\mathrm{BBC}$ de Londres le preguntó si terminaría su mandato, a lo cual respondió afirmativamente. https://ellibero.cl/alerta/presidente-pinera-dice-a-la-bbc-que-terminara-su-mandato-y-seabre-a-cambiar-la-constitucion.

27. LLANOS y MARGHERITIS (2006); MARTÍNEZ (2017a).

28. Se ha mantenido alejado del proceso constituyente, que ha lo perjudicado. Las experiencias constituyentes de antiguas y nuevas democracias (Colombia, España y África del Sur) han tenido un buen desarrollo porque el jefe de Estado ha actuado como factor de unidad nacional, favoreciendo un clima de acuerdos y compromisos entre los constituyentes que ha permitido llegar a constituciones de consenso. 
nocausal, hasta reduccionista. También es necesario considerar otros factores, entre las que destacan el contexto político, el grado de institucionalización de los partidos, los conflictos en la sociedad y el liderazgo presidencial. Esto último se explica porque la centralidad decisoria en la presidencia, como institución, le confiere al presidente, como persona, una amplia autoridad y poder, y su utilización por el mandatario puede tener enormes repercusiones en el sistema político. El análisis del estilo de liderazgo presidencial ayuda a comprender mejor el presidencialismo. El examen del liderazgo del Presidente Sebastián Piñera nos permitirá confirmar esta tesis.

El marco teórico y conceptual para el análisis del estilo de liderazgo de Piñera se apoya en los estudios de Greenstein ${ }^{29}$, el más influyente estudioso de los presidentes de los EE.UU. En sus investigaciones del liderazgo de los presidentes desde Franklin D. Roosevelt (FDR) hasta Bill Clinton identificó seis habilidades de un presidente efectivo $^{30}$. Debería ser, en primer lugar, un buen comunicador, para convencer a la opinión pública de las ventajas de sus políticas y conseguir apoyo público a éstas; poseer habilidades organizativas, que le permitan constituir un buen equipo de ministros y dirigirlo para que cada uno dé lo mejor de sí; habilidades políticas, para emplear asertivamente sus recursos de autoridad y poder, persuadiendo a otros actores a seguir sus decisiones y así lograr una reputación de hábil y resuelto operador político; visión, la capacidad para inspirar a sus votantes y a la población de los objetivos de su gobierno; un buen conocimiento de las tareas gubernamentales, con información sobre una amplísima variedad de asuntos sobre los cuales el presidente debe adoptar decisiones y evaluar el desempeño de los ministros; y, finalmente, poseer inteligencia emocional, que la definió como "la capacidad del presidente para manejar sus emociones y convertirlas en propósitos constructivos, en lugar de ser dominado por ellas y permitir que disminuyan su liderazgo" ${ }^{31}$.

La inteligencia emocional es la habilidad más importante de un presidente. Puede tener las cinco habilidades indicadas, pero sin inteligencia emocional "todo lo demás puede convertirse en cenizas" ${ }^{32}$. Greenstein distinguió tres tipos de inteligencia emocional. La primera es aquella que le permite al presidente estar básicamente libre de ser distraído por perturbaciones emocionales. La tuvieron los presidentes Eisenhower, Ford y Bush padre. Un segundo tipo de inteligencia emocional admite que se den deficiencias emocionales, aunque sin perjudicar su liderazgo. En esta situación estuvieron los presidentes Roosevelt, Truman, Kennedy y Reagan. El tercer tipo de

29. GREENSTEIN $(1982 ; 1988 ; 2000 ; 2000 a)$.

30. GREENSTEIN (2000; 2000a).

31. GREENSTEIN (2000) p. 11.

32. GREENSTEIN (2000) p. 200. Antes, comentando el liderazgo de Clinton, afirmó que él nos hace recordar que "en ausencia de inteligencia emocional, la democracia es un instrumento defectuoso de la gobernanza democrática" GREENSTEIN (2000) p. 8. 
inteligencia emocional perjudica el liderazgo. La tuvieron los presidentes Johnson, Nixon, Carter y Clinton ${ }^{33}$. Este tercer tipo de inteligencia emocional constituye una "discapacidad emocional" y puede tener consecuencias negativas en la gestión del mandatario y en el sistema político.

Para una mejor comprensión de los alcances y consecuencias de su baja inteligencia emocional, hemos recurrido a Kellerman ${ }^{34}$. Para esta autora, el liderazgo inefectivo puede basarse en tres rasgos. Puede ser un líder incompetente, cuando hay "falta de voluntad o habilidad (o ambos) para llevar a cabo una acción efectiva"; puede ser rígido, cuando "es inflexible y, aunque sea competente, es incapaz o no tiene voluntad de adaptarse a nuevas ideas, a nueva información o a los tiempos cambiantes"; y ser destemplado, es decir, "no tener autocontrol y es apoyado e inducido por colaboradores incapaces o que no desean intervenir efectivamente" ${ }^{35}$.

Piñera tiene debilidades en cada una de estas habilidades desarrolladas por Greenstein y en el caso de la inteligencia emocional, ella es notoria y constante. No se trata de bruscos cambios de ánimo, con arrebatos de ira que estremecen la oficina del presidente, como fue el Presidente Johnson. Tampoco fue la falta de control del Presidente Clinton respecto a una persona, que lo llevó a la acusación constitucional o la ira y desconfianza que tenía Nixon. Es un tipo de inteligencia emocional que se manifiesta en múltiples ocasiones, que la prensa considera anécdotas, "piñericosas". Sentarse en el escritorio del Presidente Barak Obama en la sala Oval de la Casa Blanca cuando visitó los EE.UU., escribir en el libro de invitados a la cena del presidente federal de Alemania "Deutschland, Deutschland über alles", texto eliminado del himno nacional por su abuso en el régimen de Hitler $^{36}$, hasta pasearse por una playa en un balneario de la $\mathrm{V}$ región en medio de la pandemia sin portar mascarillas, son algunos de los ejemplos.

Estas no son anécdotas irrelevantes. Dan cuenta de una baja inteligencia emocional. Destacaremos dos rasgos que han tenido enorme importancia en su liderazgo. La primera es su extrema rigidez, reiterando decisiones, discursos, hasta palabras, equivocadas, ignorando repercusiones. La segunda es su destemplanza, sin un autocontrol en cuestiones fundamentales de un gobierno democrático, entre las cuales destaca no haber separado los negocios de la política. En su oficina en La Moneda tenía cuatro pantallas, con la información de las bolsas de valores de Wall Street, de Tokio,

33. GREENSTEIN (2000) p. 199.

34. KELLERMAN (2004).

35. KELLERMAN (2004) pp. 41-42, citado por HELMS (2012) pp. 4-5.

36. La oficina de protocolo de la presidencia federal alemana pidió que se desprendiera la hoja con el saludo de Piñera y escribiera otro. 
una tercera con la información económica de la agencia Bloomberg y la cuarta, de la bolsa de Chile $^{37}$. Ejercía la presidencia pero también estaba encima de sus negocios.

Los gobiernos democráticos no fueron cuidadosos en establecer barreras institucionales para separar el dinero y la política. La puerta giratoria de ex ministros que luego fueron asesores o directores de empresas alentó esa convergencia. Tampoco tuvieron un discurso destacando la necesidad de separar los negocios de la política y condenar los casos en los cuales ello no se respetaba.

El artículo se desarrolla de la siguiente manera. Primeramente, se ubicará el tema del liderazgo en la bibliografía del presidencialismo y a la luz de la experiencia política chilena, se hará un breve recuento de la biografía del Piñera, en seguida se examinará el liderazgo de Piñera y finalmente, las conclusiones.

\section{La visión crítica de Linz del presidencialismo}

Desde el seminal artículo de $\operatorname{Linz}^{38}$, la preocupación por el presidencialismo adquirió gran ímpetu, con enfoques preferentemente institucionalistas. Sabemos bastante de la autoridad y poder del presidente ${ }^{39}$; la organización del gobierno presidencial ${ }^{40}$; la composición de los gabinetes ${ }^{41}$; el papel del congreso ${ }^{42}$, y la estabilidad del presidencialismo $^{43}$. Sin embargo, se sabe poco de los presidentes y del liderazgo presidencial ${ }^{44}$.

37. Durante el conflicto limítrofe marítimo con Perú y estaba siendo decidido por la Corte Internacional de Justicia de La Haya, una de sus empresas adquirió acciones de una empresa pesquera peruana.

38. LINZ (1994). La primera versión fue presentada en un simposio sobre Political Parties and Democratic Transitions, organizado por el Woodrow Wilson Center de Washington DC, que llevaba por título Presidential or Parliamentary Democracy. Does it Make a Difference?". Esta versión fue ampliamente difundida y fue publicada con el título y contenido una década más tarde en el libro que editó con Arturo Valenzuela: LINZ y VALENZUELA (1994).

39. SHUGART y CAREY (1992); MAINWARING y SHUGART (1997).

40. ABRANSCHES (1988); LANZARO (2003).

41. AMORIM NETO (2002); AVENDAÑO Y DAVILA (2018).

42. MORGENSTERN y NACIF (2002); ESCUDERO (2018).

43. MARTÍNEZ (2017b; 2020).

44. Hay una amplia bibliografía sobre el liderazgo político, EDINGER (1967); RUSTOW (1970); NYE JR. (2008), de los presidentes en EE.UU., destacando los libros de GREENSTEIN (1982; 1988; 2000; 2000a) y también sobre el liderazgo de primeros ministros, IONESCU (1991); HARDGROVE y OWENS (2003); BROWN (2018). Una excepción en el estudio del liderazgo presidencial de América Latina es LLANOS y MARGHERITIS (2006). 
Linz tuvo una visión crítica del presidencialismo. Argumentó que su arquitectura institucional tenía dos componentes estructurales que le impedían resolver crisis políticas graves ${ }^{45}$. Ellas eran la legitimidad dual y la rigidez del presidencialismo. La primera se refiere a las distintas mayorías surgidas de las elecciones separada de presidente y del congreso, lo cual conduciría inevitablemente a diferencias sobre proyectos de leyes que puedes escalar hasta convertirse en un conflicto de poder entre ambas instituciones. La segunda alude a que el presidente es elegido por un período fijo y se mantiene en el cargo hasta su término. A diferencia del régimen parlamentario, no dispone de un mecanismo oportuno y eficaz, que ponga término anticipadamente a un mandatario que se desempeña muy negativamente, incluso dañando la calidad de la democracia. La acusación constitucional sería el único recurso constitucional para destituir al presidente por su pésimo desempeño. Sin embargo, es un mecanismo excepcional y de compleja aplicación, que puede agravar la crisis en vez de resolverla. Por ello, agrega Linz, habría una incompatibilidad entre el presidencialismo y la democracia. Para alcanzar una democracia estable, los países con presidencialismo debieran cambiar su forma de gobierno a uno parlamentario.

La historia política de Chile en el siglo XX (y en el siglo XXI) no confirma la visión pesimista del presidencialismo que tuvo Linz. La legitimidad dual no condujo a conflictos insolubles entre el presidente y el Congreso. Todos los presidentes elegidos en elecciones libres desde 1932 debieron lidiar con un Congreso en el cual no eran mayoría. Fueron gobiernos divididos ${ }^{46}$. La única excepción fue el segundo gobierno de la presidenta Bachelet (2014-2018), que logró mayoría en las dos ramas del Congreso. Esto le permitió impulsar un ambicioso programa de reformas (educación, tributaria y laboral) que fue resistido por la oposición y obstruido en sus alcances por el Tribunal Constitucional en el caso de la reforma laboral.

En este largo período de la historia política de Chile, todos los presidentes, con mayor o menor dedicación, estuvieron dispuestos a negociar con la oposición para llevar adelante su programa. Algunos lo hicieron incorporando a partidos al gabinete; otros, con acuerdos puntuales sobre la agenda legislativa. El Presidente Jorge Alessandri, elegido en 1958 con un 31,1\% de los votos (el menor de todos los mandatarios durante la vigencia de la Constitución de 1925), negoció con el Partido Radical (PR) su elección por el Congreso Pleno y su apoyo desde el Congreso para la aprobación

45. Esta visión pesimista del presidencialismo para enfrentar crisis política fue compartida por politólogos, que mantuvieron preocupación por el quiebre de la democracia en América Latina, LLANOS y LEIV MARSTEINTREDET (2010); DOYLE (2020).

46. La renovación del Senado por mitades cada cuatro años impidió al Presidente Frei Montalva tener mayoría en la cámara alta en las elecciones parlamentarias de 1965, que logró en forma abrumadora en la cámara de diputados, en la cual el Partido Demócrata Cristiano (PDC) eligió 82 de los 150. CRUZ-COKE (1984). 
de los proyectos de ley. El gobierno del Presidente Frei Montalva impulsó la "Revolución en Libertad" ${ }^{47}$, con ambicioso programa de reformas estructurales, destacando la reforma agraria y la sindicalización campesina, sin tener mayoría en el Senado, logrando acuerdos con alguno de los partidos de oposición, de izquierda o de derecha ${ }^{48}$.

La excepción fue el conflicto de 1973, en el cual el Presidente Salvador Allende no aceptó llegar a un acuerdo con el PDC. Sin embargo, la profundidad de la crisis fue más allá que un conflicto entre el Presidente Allende y el Congreso. Había una cuestión política de fondo planteada por el programa de gobierno de la Unidad Popular de impulsar una revolución con el apoyo de una minoría del Congreso y de la ciudadanía, sin tener una práctica política que fuera congruente con el camino democrático.

El estallido social del 18-O no fue el tipo de conflicto advertido por Linz, es decir, entre el Presidente y el Congreso. Fue un conflicto entre la sociedad, por un lado, y el presidente y el Congreso por el otro lado, provocado por la crisis de legitimación del sistema económico y la crisis de representación del sistema político a los cuales nos hemos referido.

Con todo, existe otra alternativa para situaciones extremas, cuando un presidente con un muy pobre liderazgo está dañando la democracia: su dimisión. Linz considera esta alternativa como "una de las formas de evitar las implicaciones de la rigidez del mandato presidencial sin la salida de los tanques o la violencia en las calles. Sin embargo, no es una solución muy probable dada la psicología de los políticos" ${ }^{49}$.

Es una respuesta tautológica que da Linz para reforzar su tesis de la rigidez del presidencialismo. La dimisión del presidente estaba considerada en la tradición constitucional de Chile, comenzando por la Constitución de 1833 (art. 36, No 3 y 74) que la indica entre las atribuciones exclusivas del Congreso "declarar, cuando el Presidente de la República hace dimisión de su cargo, si los motivos en que la funda, le imposibilitan, o no, para su ejercicio, y en su consecuencia admitirla o desecharla". En idénticos términos se refiere la Constitución de 1925 pues incluye entre las atribuciones exclusivas del Congreso declarar si admite o desecha la dimisión del Presidente (art. 43). La Constitución de 1980 también la considera, pero la entrega como atribución exclusiva del Senado, debiendo "en ambos casos (admitirla o desecharla) deberá oír previamente al Tribunal Constitucional", que es una opinión no vinculante (art. 49, No 7).

Esta posibilidad la consideró el Presidente Arturo Alessandri en los tumultuosos días de septiembre de 1924 por la presión de los militares para que el Congreso apro-

47. Sobre el programa y la ejecución de sus principales políticas, véase HUNEEUS y COUSO (2016). 48. Con el PR negoció en el Senado los nombramientos de los embajadores; con el PC, la reforma agraria y la sindicalización campesina y con la derecha, agrupada en el partido Nacional, la reforma constitucional de 1970.

49. LINZ (1994) p. 10. 
bara "el paquete" de proyectos pendientes. La Junta militar rechazó esta alternativa, ofreciendo pedir "un permiso para ausentarse del país", lo que terminó ocurriendo ${ }^{50}$. También fue planteada en la crisis de 1973 por el Partido Nacional, que reunía a los antiguos liberales y conservadores, exigiendo la renuncia del Presidente Salvador Allende. Este se negó a ello.

Nunca el Congreso empleó esta atribución. Sí procede plantear la pregunta sobre la conveniencia de provocar la renuncia del presidente cuando tiene un pobre desempeño y ello está muy determinado por su débil inteligencia emocional, con decisiones que siguen dañando la institución presidencial y la calidad de las políticas. ¿Deben los dirigentes de la oposición y de la sociedad civil limitarse a esperar que termine el mandato del presidente, faltando dos años, porque así lo establece la Constitución? ¿No correspondería que presionaran por medios pacíficos para que dimitiera para evitar un mal mayor?

Las respuestas no son fáciles. En momentos difíciles, las presiones desde abajo pueden ser aprovechadas por grupos minoritarios que quieren ir más allá de cambiar al presidente, convencidos de que se puede provocar un cambio de régimen. Se requiere una oposición fuerte, con liderazgo, y con el acuerdo de al menos uno de los partidos de gobierno. La actual oposición es débil y fragmentada, los principales partidos no tienen liderazgos para conducir una salida como esta, habiendo fuerzas centrífugas en la derecha y en la izquierda. En definitiva, la inercia del presidencialismo impidió que se explorara esta alternativa.

La visión crítica de Linz del presidencialismo provocó un amplio debate. La revisión probablemente más documentada fue realizada por José Antonio Cheibub ${ }^{51}$. Con un cuidadoso examen de los gobiernos presidenciales y parlamentarios entre 1946 y 1999, Cheibub concluyó que el presidencialismo no conduce de manera inevitable a un conflicto entre el presidente y el congreso, y no se generará una crisis que pondrá en riesgo la continuidad de la democracia. "Las instituciones presidenciales no son la causa de la inestabilidad de las democracias presidenciales" ${ }^{52}$. La inestabilidad de las democracias presidenciales observadas por Linz, agrega Cheibub, es correcta, pero la causa que indica errada, pues aquella "se debe al hecho de que observamos instituciones presidenciales en países donde la democracia de cualquier tipo sería inestable" (nuestro énfasis ${ }^{53}$ ). La inestabilidad que se observa en las democracias presidenciales -agrega Cheibub- no proviene de su arquitectura institucional sino que de conflictos en la sociedad, particularmente de los legados de los regímenes militares. El mili-

50. VIAL (1986) p. 400; COLLIER y SATER (1998).

51. CHEIBUB (2002); CHEIBUB y LIMONGI (2002); CHEIBUB et al. (2004); CHEIBUB (2007).

52. CHEIBUB (2007) p. 6.

53. CHEIBUB (2007) p. 7. 
tarismo es una consecuencia de la estructura social o de contextos en los cuales los militares, por razones endógenas o coyunturales fueron movilizados políticamente antes que otros actores políticos ${ }^{54}$.

De ahí infiere que sería "más prudente y efectivo desde un punto de vista político tomar la forma de gobierno como un hecho dado, en vez de concentrarse en mejorar el sistema que está en el lugar y que los actores centrales dan por entendido", agregando que "el problema con la literatura que identifica al presidencialismo como la causa de la inestabilidad democrática es que pone demasiado énfasis en los principios que definen las diferentes formas de gobierno y simplemente derivan de su principio la conducta que podría o quizás debiera seguir" ${ }_{55}$.

\section{Un hombre de negocios en política}

Piñera tiene una interesante biografía, empresarial y política. De profesión economista de la P. Universidad Católica y doctor en esta disciplina en la Universidad de Harvard, regresando al país en 1976. Fue profesor de la escuela de Economía en la cual había estudiado y trabajó dos años en la CEPAL en un proyecto sobre pobreza en América Latina. Después se integró al sector privado. Trabajó en una consultora, para luego entrar al sector financiero, llegando a ser gerente general del Banco de Talca (1979-1980) y después, de Citicorp (1981-1986), el principal banco de inversiones, controlado por el grupo Cruzat ${ }^{56}$. Al mismo tiempo, desarrolló negocios propios que fueron exitosos, pero incurrió en conflicto de interés por lo cual fue alejado del cargo. A finales de la dictadura había reunido una considerable fortuna, que incrementó en democracia. En 2007 llegó a ser uno de los billonarios de la revista Forbes.

No es cualquier billonario. Su fortuna sobresale en comparación a otras personas de negocios que han alcanzado la presidencia o la jefatura del gobierno en un régimen parlamentario. El “magnate” Donald Trump tenía en 2018 un patrimonio de \$3,1 billones de dólares, un $0,02 \%$ del PIB de su país. El porcentaje del patrimonio de Trump en el PIB de EE.UU. aplicado al de Chile, reduciría su fortuna a \$59,6 millones de dólares, menor al que tuvieron varios empresarios que fueron ministros ${ }^{57}$. También supera, en término relativos, al patrimonio de Silvio Berlusconi, cinco veces presidente del Consejo de Ministros de Italia durante la década del 9o, que alcanzaba al o,36\% del PIB de Italia, es decir, casi un tercio del que tiene Piñera. El presidente de Argentina, Mauricio Macri (2015-2019), también un exitoso empresario, no era billonario cuando fue elegido y tampoco lo sería al abandonar la Casa Rosada.

\section{CHEIBUB (2007) p. 15.}

55. CHEIBUB (2007) p. 25.

56. TROMBEN (2016).

57. El porcentaje de la fortuna de Piñera en el PIB de EE.UU. representaría aproximadamente $\$ 200$ mil millones de dólares. 
Hijo de uno de los fundadores de la Falange Nacional, partido que más tarde llegó al Partido Demócrata Cristiano, votó por él No en el plebiscito de 1980 y 1988. Ingresó a la política después del plebiscito de 1988 a través de Renovación Nacional, siendo elegido senador en los comicios de 1989, cargo que desempeñó hasta 1998. Nunca antes había participado en política, ni siquiera cuando fue estudiante en la escuela de Economía de la Universidad Católica ${ }^{58}$. Haber votado por el No en 1988 fue una excepción entre los empresarios y políticos de derecha, incluyendo a los de $\mathrm{RN}$, que habían votado por el Sí.

Fue presidente de su partido (2001-2004), candidato presidencial en las elecciones de 2005, imponiéndose en la primera vuelta al candidato de la UDI, Joaquín Lavín, aunque fue derrotado en la segunda vuelta por Michelle Bachelet. Fue elegido presidente en las elecciones presidenciales de $2009^{59}$. Volvió a La Moneda en las elecciones de 2017, venciendo en segunda vuelta a Alejandro Guillier, candidato de la Nueva Mayoría, coalición que había apoyado el segundo gobierno de Michelle Bachelet (20142018).

En el Senado no se concentró en familiarizarse con el oficio de político, que desconocía. Por el contrario, siguió impulsando activamente sus negocios, distribuidos en decenas de sociedades, con la finalidad de incrementar su fortuna. Impulsar sus inversiones e impulsar su carrera a la presidencia fueron dos actividades estrechamente ligadas entre sí, que se complementaban porque empleó la información y el poder que adquirió como senador para fortalecer sus negocios ${ }^{60}$. Aquí hubo un grave problema de conflicto de interés, sobre lo cual volveremos.

Piñera no es un político propiamente tal, aquel que se ha dedicado por años a este oficio, viviendo para y de la política en la clásica definición de Max Weber ${ }^{61}$, que le apasione y quiera dominar, interiorizándose de sus normas formales e informales. Entró muy tardíamente a ella -después del plebiscito del 5 de octubre de 1988-. Lo hizo desde los negocios, habiendo acumulado una fortuna en los años 80 durante la dictadura, especialmente en el sector financiero. Consideró que, habiendo llegado a ser millonario, su próximo gran objetivo sería alcanzar la presidencia de la república. Avanzó en esa dirección sin separarse de los negocios.

58. El comienzo de la biografía de numerosos políticos en Chile ha sido en el movimiento estudiantil.

59. Derrotó en la segunda vuelta al ex Presidente Eduardo Frei Ruiz-Tagle (PDC, 1994-2000), candidato de la Concertación, coalición de centroizquierda que ocupó la presidencia entre 1990 y 2010.

60. Cuando fue presidente de RN las reuniones de la directiva no las hacía en la sede del partido, sino en su oficina en la cual estaban la dirección de sus empresas. DAZA y DEL SOLAR (2017).

61. WEBER (1982). 


\section{Las debilidades del liderazgo del presidente Piñera}

A continuación examinaremos los atributos del liderazgo presidencial de Piñera. La habilidad de comunicador del presidente se expresa principalmente a través de discursos, entrevistas y declaraciones a los medios de comunicación. Piñera no es un buen comunicador. Pronunció numerosos discursos durante el estallido social, pero sin lograr convencer a quienes lo escucharon: 30 entre el 18 de septiembre y el 18-O (en 27 días, más de uno por día) y 28 entre el 18-O y el 31 de enero de 2020 . También pronunció numerosos discursos durante la pandemia. (Tabla 1).

Tabla 1. Número de discursos de Sebastián Piñera y extensión (18/o9/2019 31/01/2020 y 03/03/2020 -14/08/2020).

\begin{tabular}{|c|c|c|}
\hline Días & $\mathbf{N}^{\circ}$ de discursos & $\mathbf{N}^{\circ}$ de palabras \\
\hline $18 / 09 / 2019-17 / 10 / 2019$ & 30 & 44.096 \\
\hline $18 / 10 / 2019-31 / 01 / 2020$ & 28 & 37.469 \\
\hline $03 / 03 / 2020-14 / 08 / 2020$ & 64 & 66.318 \\
\hline Total & 119 & 147.883 \\
\hline
\end{tabular}

Fuente: Elaboración propia a partir de https://prensa.presidencia.cl/ y de Navarro \& Tromben (2019).

En sus numerosos discursos se muestra muy informado de una amplísima variedad de temas, entregando abundantes antecedentes. Sin embargo, no consigue empatía en la población. Sus discursos son reiterativos en los temas y en los énfasis, incluso, de ciertas palabras. No concede conferencias de prensa. Suele dar entrevistas en radio y televisión individuales, mostrando tener un amplio conocimiento de los temas. Su debilidad como comunicador político explica su baja popularidad en las encuestas. Es el presidente con menor apoyo popular desde 1990 (Figura 1).

La segunda habilidad que debe poseer un presidente efectivo es capacidad organizativa. El Presidente debe estructurar un buen equipo de ministros y dirigir su trabajo para obtener lo mejor de sus capacidades. También requiere conocimiento de la implementación de las políticas y el papel de la administración pública en ello. No reúne esta habilidad. Su experiencia en el mundo de los negocios fue tomar decisiones individualmente sobre inversiones a partir de la información requerida que le preparaba un reducido y destacado grupo de jóvenes economistas ${ }^{62}$.

Como no conocía el mundo político de la derecha, buscó a sus ministros preferentemente del sector privado, entre altos ejecutivos, directores o consultores de empresas. Diez de los 22 ministros del primer gabinete en su primer gobierno tuvieron ese perfil. En su segundo mandato, la participación de ministros provenientes del sector

62. DAZA y DEL SOLAR (2017). 
privado fue similar, ocho de los 22. Llama la atención que en su segundo gobierno reclutó pocos ministros del primero, que poseían una cierta experiencia política (Tabla 2).

Tabla 2. Número de ministros del II gobierno de Piñera que no estuvieron en el I gobierno.

\begin{tabular}{|l|c|}
\hline \multicolumn{1}{|c|}{ Categorías } & Nuevos ministros \\
\hline 1. Primer gabinete Piñera II respecto del total de Piñera I & 17 de 23 \\
\hline $\begin{array}{l}\text { 2. Ministros del ultimo gabinete Piñera II respecto del total de } \\
\text { Piñera I }\end{array}$ & 19 de 24 \\
\hline $\begin{array}{l}\text { 3. Total ministros gobierno Piñera II respecto del total de min- } \\
\text { istros de su I gobierno }\end{array}$ & 34 de 45 \\
\hline
\end{tabular}

Fuente: Elaboración propia. Los datos fueron recabados al 31 de agosto de 2020.

Trabaja en forma individual, revisando las propuestas de políticas enviadas desde los ministerios y reunidas en carpetas. No delega poder en los ministros, pues revisa cada una de sus propuestas de políticas. Acumula en su escritorio decenas de carpetas con los antecedentes de decisiones de ministerios que esperan su aprobación, desde complejos proyectos de leyes, hasta nombramientos de embajadores o consejeros de organismos de administración autónoma, cuya decisión demora, con la consiguiente menor eficacia del gobierno ${ }^{63}$.

Cuando surgen dificultades, no se esfuerza por buscar la solución, sino que cambia al ministro. Ello explica los frecuentes cambios de gabinete y de ministros. En un año ha tenido cuatro ministros del Interior y tres ministros de SEGPRES (octubre 2019 a noviembre 2020), sin que se haya llevado adelante la anunciada reforma de Carabineros.

La tercera es la habilidad política, corresponde al poder presidencial según Neustadt ${ }^{64}$, que se expresa en la capacidad del mandatario de persuadir a sus ministros, parlamentarios y a otros actores políticos de que es un hábil negociador. Esta habilidad requiere conocer los recursos de autoridad y poder que dispone. Piñera contó con pocos recursos de autoridad porque era un presidente minoritario en tres dimensiones: electoral, en el Congreso y en las encuestas. Sin embargo, no asumió este hecho, sin esforzarse por impulsar acuerdos con la oposición. Pareciera que nunca fue senador.

En la elección del 2017 se impuso en segunda vuelta con una amplia mayoría, $54,57 \%$. Sin embargo, constituía una minoría del electorado (26,5\% del padrón), pues, como se dijo, votó un 49,1\% de éste (Tabla 3). Esta mayoría la logró con el apoyo de

63. El retraso en los nombramientos de subsecretarios y embajadores al comienzo del segundo gobierno se prolongó por meses.

64. NEUSTADT (1960). 
José Antonio Kast, el cual en la primera vuelta obtuvo casi el $8 \%$ de los votos. Piñera no valoró su apoyo e ignoró sus propuestas. En 2020, Kast se declaró estar en la oposición, acusándolo de no cumplir el programa que ofreció al país.

La baja votación que recibió Piñera se aprecia en una perspectiva histórica, pues fue un número menor de votos que el obtenido por el Presidente Patricio Aylwin tres décadas antes, cuando el padrón electoral era aproximadamente la mitad. Piñera recibió 3.796.579 votos con un padrón electoral de 14.347.288 personas; Aylwin recibió 3.850 .571 sufragios con un padrón de 7.557.537 personas $^{65}$.

El regreso de Piñera a La Moneda en 2018 fue sorprendente. Su gestión en el primer gobierno fue deficiente, que condujo a la aplastante derrota en las elecciones de 2013 de Evelyn Matthei, ex ministra del Trabajo de Piñera y abanderada de la derecha. También se produjo la caída del electorado de los partidos de gobierno. En la primera vuelta electoral Matthei obtuvo 25,03\% de los votos, siendo superada ampliamente por Michelle Bachelet, abanderada de la Nueva Mayoría, con 46,70\%. En la segunda vuelta, Matthei subió al 37,83\% y Bachelet alcanzó 62,17\%.

Tabla 3. Resultados de las elecciones presidenciales del 2009, 2013 y 2017.

\begin{tabular}{|c|c|c|c|}
\hline & Candidatos & Votos & (\%) \\
\hline Primera vuelta 2009 & S. Piñera & 3.074 .164 & 44,06 \\
& E. F. Ruiz-Tagle & 2.065 .061 & 29,60 \\
& M. Enríquez-Omi- & 1.405 .124 & 20,14 \\
& nami & 433.195 & 6,21 \\
& J. Arrate & & \\
\hline Segunda vuelta & S. Piñera & 3.591 .182 & 51,61 \\
2009 & E. F. Ruiz-Tagle & 3.367 .790 & 48,39 \\
\hline Primera vuelta 2013 & M. Bachelet & 3.075 .839 & 46,70 \\
& E. Matthei & 1.648 .481 & 25,03 \\
& E. & 723.542 & 10,99 \\
& Enríquez-Omi- & 666.015 & 10,11 \\
& F. Parisi & 185.072 & 2,81 \\
& M. Claude & 154.648 & 2,35 \\
& A. Sfeir & 81.873 & 1,24 \\
& R. Miranda & 37.744 & 0,57 \\
& R. Israel & 12.594 & 0,19 \\
& T. J. Holt & & 62,17 \\
\hline \multirow{2}{*}{ vuelt3 } & M. Bachelet & 3.470 .370 & 37,83 \\
\hline
\end{tabular}

$\overline{65 . \text { Es la población en edad de }}$ votar, porque la inscripción no era automática. 


\begin{tabular}{|c|c|c|c|}
\hline Primera vuelta 2017 & $\begin{array}{c}\text { S. Piñera } \\
\text { A. Guillier } \\
\text { B. Sánchez } \\
\text { J. A. Kast } \\
\text { C. Goic } \\
\text { M. Enríquez-Omi- } \\
\text { nami } \\
\text { E. Artés } \\
\text { A. Navarro }\end{array}$ & $\begin{array}{c}2.417 .216 \\
1.497 .116 \\
1.336 .824 \\
523.213 \\
387.780 \\
376.471 \\
33.690 \\
24.019\end{array}$ & $\begin{array}{c}36,64 \\
22,70 \\
20,27 \\
7,93 \\
5,88 \\
5,71 \\
0,51 \\
0,36\end{array}$ \\
\hline $\begin{array}{c}\text { Segunda } \\
2017\end{array}$ & $\begin{array}{l}\text { S. Piñera } \\
\text { A. Guillier }\end{array}$ & $\begin{array}{l}3.796 .579 \\
3.159 .902\end{array}$ & $\begin{array}{l}54,57 \\
45,42\end{array}$ \\
\hline
\end{tabular}

Fuente: Elaboración propia con datos del Servel, https://www.servel.cl/.

Desde el 31 de enero de 2012 rige la Ley $\mathrm{N}^{\circ} 20.568$ que incorpora el voto voluntario.

En segundo lugar, era minoritario en las dos cámaras del Congreso. Era un gobierno dividido, como fueron los que tuvo Chile desde 1932, con excepción del segundo gobierno Bachelet. Piñera nunca se propuso buscar un acuerdo con algún partido de oposición, ni siquiera en los difíciles momentos del estallido social. No tenía la habilidad de negociador. Estaba acostumbrado al mundo de los negocios, en el cual tomaba decisiones sin preguntarle a nadie. Tampoco durante la pandemia Piñera buscó un acuerdo con la oposición, a diferencia del liderazgo de otros presidentes, como el de Uruguay, Luis Lacalle Pou, que asumió en marzo de 2020. Tampoco durante el proceso constituyente.

En tercer lugar, Piñera tuvo una baja aprobación en las encuestas, que puede ser comprensible en su limitado electorado que obtuvo en primera vuelta, que expresan los votos de los partidos de derecha. Desde que entró a La Moneda comenzó a caer en las encuestas y desde agosto de 2019 se mantuvo por debajo del 30\% de popularidad (Figura 1). 
Figura 1. Popularidad del Presidente Sebastián Piñera (2018-2002)

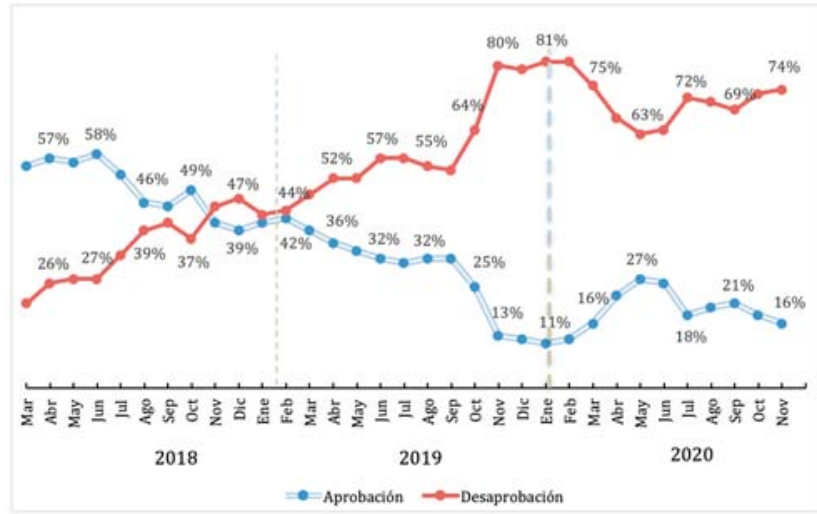

Fuente: Elaboración propia a partir de "Encuesta Plaza Pública Cadem" https://www.cadem.cl/. Los datos corresponden a la aprobación presidencial mensual que realiza Cadem a partir de las cifras semanales que recaban.

Piñera no tuvo una visión de la presidencia. Preparó el programa con numerosos profesionales, sin tener orientaciones programáticas que dieran cuenta de su visión de las necesidades del país. Esta no se reduce a la formulación de un conjunto de policies, que corresponde más bien a la visión tecnocrática de la política ${ }^{66}$.

Piñera no tiene un buen estilo de conocimiento. Según el diccionario de la Real Academia Española conocer es "averiguar por el ejercicio de las facultades intelectuales la naturaleza, cualidades y relaciones de las cosas”. Es una acción más compleja que reunir información de las múltiples acciones de gobierno; significa identificar sus prioridades, la interrelación entre las políticas y su viabilidad de ejecución. Posee una gran capacidad para estudiar y retener con gran rapidez una amplísima cantidad de información. Sin embargo, lo hace ordenadamente, pero en forma fragmentada, sin considerar las interrelaciones y contradicciones que existen entre las políticas. Esta debilidad es una consecuencia de su estilo de trabajo que desarrolló en sus años de hombre de negocios, durante los cuales se familiarizó con los estados financieros de decenas de empresas, nacionales y extranjeras, que son independientes, con un nivel de conocimiento que sorprendía a quienes trabajaron con él ${ }^{67}$. Esta práctica la mantuvo al ingresar a la política, en el Senado y cuando fue presidente. La información de cada política de gobierno era reunida en una carpeta, para que fuera revisada

66. CARAMANI (2017).

67. Preguntado por uno de los autores un empresario que se relacionó con él en el mundo de los negocios cuántas empresas conoce bien sus estados financieros, si acaso podían ser 20 o 30, respondió de inmediato, " 50 ", dando a entender que su número podía ser incluso superior a este último. 
por Piñera. En su escritorio se acumulaban decenas de carpetas, colmando todos los espacios. La fotografía de su escritorio en La Moneda con sus carpetas pone de manifiesto su estilo de conocimiento ${ }^{68}$.

Sin embargo, este estilo de conocimiento no le ayuda en su labor de presidente. Refuerza su convicción de saber todo y sobre todo, más incluso que sus ministros y los políticos de oposición que le piden los reciba para tratar algún tema ${ }^{69}$. Los ministros de Piñera son bastante más jóvenes que él y se inhiben de plantearle sus puntos de vista cuando difieren de las suyas. Piñera se rodea de personas que opinan como él, confirmando sus decisiones.

Dijimos que Greenstein considera la inteligencia emocional como la principal habilidad del presidente. Su debilidad dañará a las otras, por muy sólidas que sean. Piñera tiene una débil inteligencia emocional, llegando a ser una discapacidad emocional. Ha dañado su liderazgo y ha tenido altos costos para el sistema político. Dos rasgos del liderazgo ineficiente según Kellerman ${ }^{70}$ nos sirven para conocer su débil inteligencia emocional: la rigidez y ser destemplado.

\section{La rigidez frente al estallido social}

Una de las principales manifestaciones de su rigidez fue el diagnóstico que tuvo del estallido social, reducido a una cuestión de orden público. No se interesó por su carácter de coyuntura crítica, con una crisis de legitimidad del sistema económico y el sistema político tiene una crisis de representación. Por la noche del 18-O, decretó el Estado de emergencia en Santiago con la finalidad de restablecer el orden público y nombró a un general de Ejército a su cargo. Por primera vez desde la dictadura de Pinochet los militares salieron a las calles con ese objetivo, un hecho del mayor simbolismo político porque en un amplio segmento de la ciudadanía estaba viva la memoria de esos años ${ }^{71}$.

Rompió su silencio a las o:15 AM del día 19 con un breve discurso, al anunciar el Estado de emergencia y otro por la tarde. En ambos, condenó los hechos de violencia, sin referirse a las demandas de la ciudadanía. Al segundo día, el 20 de octubre por la noche, pronunció un extenso discurso, (el tercero) en el cual el presidente se extendió

68. La fotografía del Presidente Piñera trabajando en su escritorio apareció en El Mercurio y La Tercera. https://www.latercera.com/la-tercera-pm/noticia/el-silencioso-trabajo-de-la-presidenciaen-contenidos-constitucionales-hasta-donde-puede-involucrarse-pinera/2YABZVM3WJBOXNL WLJJKTZFH5Q/.

69. Entrevista con un diputado opositor, presidente de una de las comisiones de la Cámara, 31 de agosto de 2020.

70. KELLERMAN (2004).

71. Fue el primer Estado de excepción constitucional en la capital de Chile desde 1990. 
en su condena a la violencia, nuevamente sin considerar las demandas de la ciudadanía. Para él, todo se reducía a un problema de orden público, provocado por delincuentes y grupos violentistas. Sus palabras estaban lejos de contribuir a la paz social:

"Estamos en guerra contra un enemigo poderoso, implacable, que no respeta a nada ni a nadie y que está dispuesto a usar la violencia y la delincuencia sin ningún límite, que está dispuesto a quemar nuestros hospitales, el metro, los supermercados, con el único propósito de producir el mayor daño posible ${ }^{\prime \prime 2}$.

El restablecimiento del orden público y la seguridad de las personas fue su prioridad ante el estallido social, que reiteró en numerosas ocasiones e insistiendo sobre ello varias veces en cada discurso. La primera vez que lo señaló fue el 19 de octubre cuando decretó Estado de Emergencia y al momento de anunciar la suspensión del alza del pasaje en el transporte público... "La primera prioridad de nuestro Gobierno es asegurar el orden público y la seguridad de los chilenos, y también el resguardo de las libertades y de los derechos que corresponden a todos nuestros compatriotas"73.

Incluso cuando se refirió al Acuerdo por la Paz y la nueva Constitución destacó la importancia de resguardar el orden público:

El Acuerdo por la Paz no significa solamente resguardar el orden público y la seguridad ciudadana, significa mucho más, significa también fortalecer la amistad cívica entre todos los chilenos, significa regirse por el Estado de Derecho y respetar la ley, significa respetar los Derechos Humanos de todos, significa pacificar los espíritus, de forma que usted y su familia y todas las familias chilenas puedan vivir, estudiarse, trabajar o recrearse en paz, con seguridad y así poder ejercer en plenitud su libertad y sus derechos ${ }^{74}$.

En síntesis, no tiene capacidad de adaptarse a los cambios porque no los toma en cuenta. Esta rigidez constituye una severa limitación a su liderazgo.

\section{Templanza puesta a prueba: Negocios y política}

La segunda manifestación de su discapacidad emocional fue ser destemplado, en particular, en un tema central de la democracia: separar los negocios de la política. Es propio del autoritarismo no admitir la separación entre los bienes públicos y los inte-

72. Disponible en: https://www.cooperativa.cl/noticias/pais/manifestaciones/presidente-pineraestamos-en-guerra-contra-un-enemigo-poderoso/2019-10-20/232318.html.

73. Énfasis nuestro y en las siguientes citas. Prensa presidencia (19 de octubre de 2019). https:// prensa.presidencia.cl/comunicado.aspx?id=103668.

74. Prensa presidencia (17 de noviembre de 2019). https://prensa.presidencia.cl/discurso. aspx?id=134637. 
reses personales, habiendo una fusión entre ambos. En democracia, esa separación es de la esencia del Estado de derecho y de una economía de mercado. Como decíamos antes, Piñera nunca se planteó que hubiera un conflicto de interés entre su calidad de senador e inversionista. Tampoco cuando era presidente. Hubo importantes proyectos de ley en los cuales intervino y que le beneficiaron (reforma tributaria de 1990), y realizó inversiones favorecido por ser senador ${ }^{75}$.

Hasta en los primeros meses de su primer gobierno (2010-2014), se negó a separarse de sus negocios y a entregar la administración de sus inversiones a un fideicomiso ciego. Finalmente lo hizo, pero cedió solo una parte de su patrimonio, sin dejar de estar preocupado del estado de sus inversiones.

La mayor manifestación de su destemplanza ocurrió cuando era senador y adquirió el $24 \%$ del capital de LAN que licitó la Corfo, que era el resto que permanecía en poder del Estado después de su privatización en los años 8o. Como ha documentado Tromben $^{76}$, Piñera se preocupó que las AFP no participaran en la licitación, pues eran las principales adquirentes de los paquetes de acciones de las privatizaciones de las empresas públicas y del "área rara" desde 1985. Para ese fin, dos semanas antes del remate realizado el 23 de mayo de 1994, Piñera dio una conferencia de prensa "atacando duramente el sistema de AFP [y] centró su ofensiva en los costos exageradamente altos y el excesivo traspaso de afiliados entre AFP" ${ }^{77}$. Estas declaraciones del principal senador de la oposición fueron suficientes para convencer a las AFP de no participar en el remate. Hubo un solo interesado, una empresa vinculada a su socio histórico, quien era el principal accionista de $\mathrm{LAN}^{78}$.

Esta fue una inversión extraordinariamente rentable para Piñera, pues le permitió ser uno de los socios controladores de una empresa que creció en forma espectacular. Los buenos resultados de la empresa llevaron a Piñera a aumentar su participación en LAN. En 2006, adquirió un paquete de acciones que representaban 0,94\% del capital y lo hizo luego de conocer los favorables estados financieros de la empresa antes que se hiciesen públicos. Fue sancionado por la SVS en 2009, durante la campaña presidencial. Piñera pagó la multa, sin ser perjudicado electoralmente por este episodio. Venderá su participación en LAN a un precio inmensamente superior al que pagó por ella, que le permitió incrementar de manera sustancial su patrimonio y superar el billón de dólares.

Su fortuna fue un recurso de enorme importancia para su carrera a La Moneda, pues le permitió financiarla y fortalecer su poder en RN y después, en la UDI, contri-

75. TROMBEN (2016); JARA ROMÁN (2018); GUZMÁN y ROJAS (2017).

76. TROMBEN (2016).

77. TROMBEN (2016) pp. 435-436.

78. TROMBEN (2016) p. 437. 
buyendo al financiamiento de las campañas de los parlamentarios que le apoyaban. Este poder adquirió mayor relevancia porque no existió el financiamiento público de los partidos hasta la ley de 2015. Si bien el financiamiento público de campañas de parlamentarios se encontraba regulado por ley desde 2003, esta era insuficiente. Como la naturaleza le tiene miedo al vacío, también lo es en la política: surgió una red de financiamiento ilegal de la política a candidatos al Congreso de todos los partidos (con la excepción del PC), y a la presidencia de la República en las elecciones del 2009 y 2013 con aportes de grupos económicos y grandes empresas. Este financiamiento de la política fue doblemente ilegal: no había una ley y, además, se hizo a través de delitos tributarios. Los gobiernos de Aylwin y de Frei Ruiz-Tagle no cuestionaron los conflictos de interés que tuvo entre sus negocios y su labor legislativa. Tampoco lo hicieron los partidos de la Concertación ${ }^{79}$. Piñera aprovechó el hecho que la Concertación no tenía mayoría en el Senado, para darle apoyo en proyectos de leyes prioritarios para el gobierno ${ }^{80}$.

\section{A manera de conclusión}

El proceso constituyente ha provocado un debate sobre los problemas que afectan a la democracia en Chile hoy. Algunos constitucionalistas, cientistas políticos y economistas sostienen que el presidencialismo estaría en crisis, tesis que fundamentan con distintos argumentos. Unos sostienen que la crisis del presidencialismo se expresa en que se ha llegado a un hiperpresidencialismo ${ }^{81}$, por la concentración de la autoridad y poder en el presidente de la República, que debilita la separación de poderes, limita la representación política a través del Congreso y dañaría la calidad de la democracia. Otros plantean que la crisis del presidencialismo se debería a que se ha llegado a un parlamentarismo de facto, porque el Congreso ha expandido su poder por decisiones de los parlamentarios de la oposición y parlamentarios "díscolos" de los partidos de la coalición que apoyan al gobierno de Sebastián Piñera, atribuyéndose atribuciones exclusivas del presidente de la República. El presidente tendría su autoridad limitada por la injerencia del Congreso en su ámbito propio de atribuciones.

\footnotetext{
79. Eduardo Frei Ruiz-Tagle desde un comienzo el conflicto de interés que había cuando decidió entrar a la política en 1979 después de la muerte de su padre, el ex Presidente Eduardo Frei Montalva. Era empresario y socio del grupo Sigdo Koppers. Vendió su participación en el holding y entregó su patrimonio a un fideicomiso ciego, del cual él se mantuvo alejado hasta después que abandonó su carrera política.

80. Edgardo Boeninger, ministro SEGPRES del Presidente Aylwin, manifestó su reconocimiento a Piñera: "El acuerdo (tributario) se vio facilitado por el predominio sin contrapeso que en materias económicas tenía entonces en RN el Senador Sebastián Piñera (votante del NO en el plebiscito)". BOENINGER (1997) p.478, nota 94.
}

81. EYZAGUIRRE et al. (2020). 
Unos y otros coinciden en la necesidad de terminar con la tradición del presidencialismo iniciada desde que Chile es una república independiente. Se debiera cambiar la forma de gobierno adoptando el semipresidencialismo según el caso de Francia o establecer el parlamentarismo. Arturo Valenzuela ${ }^{82}$ había ido antes que estos críticos del presidencialismo afirmando que este había fracasado en Chile y era necesario introducir el parlamentarismo después de Pinochet para alcanzar una democracia estable. "El punto de partida (de este cambio de la forma de gobierno) debe ser el reconocimiento de que el régimen presidencial en Chile fracasó...(S)i el régimen de Chile hubiera sido parlamentario, no se hubiera producido el quiebre de 1973" afirmaba Valenzuela ${ }^{83}$. La tesis de la crisis del presidencialismo reivindicaría el antiguo argumento de Juan Linz ${ }^{84}$ de que esta forma de gobierno tiene componentes estructurales que no hacen posible una democracia estable.

No compartimos la tesis de la crisis del presidencialismo. Como hemos argumentado en el artículo existe una crisis de la presidencia de Sebastián Piñera, que se explica por su estilo de liderazgo, que ha dañado la institución presidencial y el proceso político. En consecuencia, el problema político de Chile no se resuelve a través de cambiar la forma de gobierno, sino a través de enfrentar los problemas que dieron origen al estallido social, configurando una coyuntura crítica. Esta se define por una crisis de legitimación del sistema económico y una crisis de representación del sistema político. En pocas palabras, es necesario introducir reformas al "modelo" siguiendo otro paradigma al actual, que sigue siendo de neoliberalismo radical ${ }^{85}$. Esto remite a las bases económicas de la democracia.

Para alcanzar una democracia sin adjetivo, una democracia moderna, cambiar la forma de gobierno no es relevante. Para ello se necesita poner atención a otros componentes institucionales, que se encuentran en "las arenas de la democracia", una de las cuales es el sistema económico ${ }^{86}$. Como se ha dicho, este no se legitimó por los buenos resultados macroeconómicos. Hubo un alto crecimiento, disminuyó la pobreza y los chilenos tuvieron mejores condiciones de vida como nunca antes. Sin embargo, no satisfizo sus expectativas: predominan los bajos salarios, trabajos inestables, altos costos por los bienes públicos proveídos por instituciones privadas y bajísimas pensiones. La percepción que el crecimiento beneficiaba a los más ricos se mostró en los años de mayor crecimiento de la economía ${ }^{87}$.

82. VALENZUELA (1985).

83. VALENZUELA (1985) p. 48.

84. LINZ (1994).

85. HUNEEUS (2017).

86. LINZ y STEPAN (1996).

87. Nos remitimos a las encuestas del CERC y a HUNEEUS (2003). 
Uno de los principales problemas del sistema económico es el de las desigualdades. Esta es una de las principales fuentes del conflicto político en el siglo XXI, similar a lo que fue en el siglo XX el conflicto de clases como advirtió Inglehart ${ }^{88}$. Las desigualdades son mayores que en los otros países de América Latina, con excepción de Brasil, y son muy altas entre los de la OCDE. El 1\% más rico concentra un 28,7\% del ingreso, muy superior a los demás países de la base de datos de Piketty y Sáez, en los cuales ningún país llega al 20\%. Si se considera un grupo más reducido de personas, el o,1\%, la concentración del ingreso alcanza al 13,7\%, más alta que la que existe en EE.UU., 10,5\%. Aún más, si se examina el ingreso que posee un porcentaje menor de la población, el o,01\% (unas 1.700 personas), ellas concentran el 6,2\% del ingreso, bastante superior al que tiene ese mismo porcentaje de individuos en los EE.UU., que alcanza al 4,4\%, muy superior a los países de América Latina considerados en el anexo (con excepción de Brasil) y las democracias avanzadas ${ }^{89}$.

Un segundo rasgo de las desigualdades económicas resalta sus considerables efectos políticos. Las desigualdades en Chile no están dispersas, es decir, el poder político está separado del poder económico, que Dahl ${ }^{90}$ consideró como un requisito fundamental de una democracia pluralista. Por el contrario, las desigualdades están acumuladas, es decir, los billonarios y los superricos disponen simultáneamente de poder económico y poder político. Los billonarios y superricos controlan las principales organizaciones empresariales ${ }^{91}$ y otros tienen poder político para influir en la agenda pública a través del control de medios de comunicación o de la influencia en sus controladores a través del avisaje ${ }^{92}$. Los grupos de interés empresarial no se encuentran frente a organizaciones sindicales influyentes, como en Argentina, Brasil y hasta en los EE.UU. Son muy débiles, lo cual refuerza el poder político de aquellas y una agenda que no enfrenta las desigualdades.

El sucesor del Presidente Piñera se encontrará con una presidencia debilitada, un sistema político aún más afectado por la crisis de representación que lo que estaba al comienzo de este gobierno y una nueva Constitución, que surgirá de un complejo proceso constituyente y en el cual Piñera se ha mantenido al margen. Además, el sis-

88. INGLEHART (2016).

89. Los datos de Chile son de ENGEL (2013).

90. DAHL (1961).

91. El presidente de la Sofofa, la influyente organización de los industriales, pertenece a la familia controladora del grupo Matte, uno de los tres más importantes; en su consejo directivo están el presidente de otro de los principales grupos económicos y altos ejecutivos de éstos.

92. Un billonario (Saiéh) controla una cadena de diarios y radios; otro (Luksic), un canal de TV y radios. La Cámara Chilena de la Construcción (CChC) compró en 2018 una radio. Otros superricos financian centros de estudios de derecha (CEP, Instituto Libertad y Desarrollo, la Fundación para el Progreso, Horizontal, entre otros. 
tema económico cargará no solo con la baja legitimidad de antes del estallido social, sino también con el impacto de la crisis económica producida por la pandemia y la defectuosa gestión de Piñera. Estos legados del segundo gobierno de Piñera se pueden atribuir a su estilo de liderazgo. Institutions matter, pero los presidentes pueden limitar sus alcances y hasta dañarlas. Es lo que ha tratado de mostrar este artículo.

\section{Referencias bibliográficas}

ABRANSCHES, Sergio (1988): "Presidencialismo de Coalizao: O Dilema Instituciona Brasileiro", Dados, año 31, No 1, pp. 5-38.

AMORIM NETO, Octavio (2002): "Presidential Cabinets, electoral cicles, and coalition discipline", en: Morgenstern, Scott y Nacif, Benito (ed.) Legislative Politics in Latin America. Cambridge: Cambridge University Press, pp.48-78.

AVENDAÑO, Octavio y DÁVILA, Mireya (2018): “Together we govern. Portafolio allocation in Chile (1990-2014)". En MARTÍNEZ-GALLARDO, Cecilia \& CAMERLO, Marcelo (eds.). Government Formation and Minister Turnover in Presidental Cabinets. Comparative Analysis in the Americas. Londres: Routledge, pp. 90-110.

AVENDAÑO, Octavio y ESCUDERO, María Cristina (2020): "Estallido social, crisis política y solución constitucional en Chile. Lecciones a partir del 18 de octubre de 2019". Ecuador Debate, pp. 156-139.

BOENINGER, Edgardo (1997): Democracia en Chile. Lecciones para la gobernabilidad. Santiago: Editorial Andrés Bello.

BROWN, Archie (2018): El mito del líder fuerte. Liderazgo politico en la Edad Moderna. S/l Los confusos del círculo de tierra.

CARAMANI, Daniele (2017): "Will vs. Reason: The Populist and Technocratic Forms pf Political Representation amd Their Critiques to Party Government". American Political Science Review, año $111 \mathrm{~N}^{\circ}$ 1, pp. 54-67.

CASTIGLIONI, Rossana y ROVIRA KALTWASSER, Cristóbal (2016): "Introduction. Challenges to Political Representation in Contemporary Chile", en: Journal of Politics in Latin America, año $8 \mathrm{~N}^{\circ} 3$, pp. 3-24.

CHEIBUB, José Antonio (2007): Presidentialism, Parliamentarianism, and Democracy. Cambridge: Cambridge University Press.

CHEIBUB, José Antonio, PRZEWORSKI, Adam y SAIEGH, Sebastián (2004): “Government Coalitions and Legislative Success Under Presidentialism and Parliamentarism“. British Journal of Political Science año 34, pp. 565-587. 
CHEIBUB, José Antonio (2002): "Minority Governments, Deadlock Situations, and the Survival of Presidential Democracies", Comparative Political Studies, año 35 $\mathrm{N}^{\circ} 3$, pp. 284-312.

CHEIBUB, José Antonio y LIMONGI, Fernandi (2002): "Democratic Institutions and Regime Survival: Parliamentary and Presidential Democracies Reconsidered". American Review of Political Science, $\mathrm{N}^{\circ}{ }_{5}$, pp. 151-179.

COLLIER, Ruth Berins y COLLIER, David (1991): Shaping Political Arena. Princeton: Princeton University Press.

COLLIER, Simon y SATER, William (1998): Historia de Chile, 1808-1994. Cambridge: Cambridge University Press.

CRUZ-COKE, Ricardo (1984): Historia electoral de Chile 1925-1973. Santiago: Editorial Jurídica de Chile.

DAHL, Robert A. (1961): Who governs? Democracy and Power in an American City. New Haven: Yale University Press.

DAZA, Loreto y DEL SOLAR, Bernardita (2017): Piñera. Biografía no autorizada. Edición actualizada. Santiago: Debate.

DOYLE, David (2020): "Breakdown, Cooperation, or Backsliding? A Return to Presidents and Legislatures in Latin America”. Latin American Research Review, año $55 \mathrm{~N}^{\circ} 1$, pp. 168-175.

EDINGER, Lewis J. (ed.) (1967): Political Leadership in Industrialized Societies. Nueva York: John Wiley \& Sons, Inc.

ENGEL, Eduardo (2013): "El uno por ciento: Chile y el mundo", La Tercera, 5 de octubre de 2013.

ESCUDERO, María Crisitina (2018): "El Congreso Nacional: organización y funciones”, en: HUNEEUS, Carlos y AVENDAÑO, Octavio (eds.). El sistema político de Chile. Santiago: Lom, pp. 119-152.

EYZAGUIRRE, Nicolás, FIGUEROA, Pamela y JORDÁN, Tomás (2020): Crisis del hiper-presidencialismo chileno: ¿Cambio de régimen político. Santiago: Flacso.

FFRENCH-DAVIS, Ricardo (2018): Reformas económicas en Chile, 1973-2017. Santiago: Taurus, Sexta edición.

GREENSTEIN, Fred I. (1982): The Hidden-Hand Presidency: Eisenhower as Leader. Nueva York: Basic Books. 
GREENSTEIN, Fred I. (ed.) (1988): Leadership in the Modern Presidency. Cambridge: Harvard University Press.

GREENSTEIN, Fred I. (200o): The Presidential Difference. Leadership Style from FDR to Clinton. Princeton: Princeton University Press.

GREENSTEIN, Fred I. (2oooa): “The Qualities of Effective Presidents: An Ovrview from FDR to Bill Clinton”. Presidential Studies Quarterly, año $30 \mathrm{~N}^{\mathrm{o}}$ 1, pp. 178-185.

GUZMÁN, Juan Andrés y ROJAS, Jorge (2017): Empresarios zombies. La mayor elusión tributaria de la élite chilena. Santiago: Catalonia-UDP Periodismo.

HARDGROVE, Edwin C. y OWENS, John E., (eds.) (2003): Leadership in Context. Oxford: Rowman \& Littlefield Publishers, Inc.

HELMS, Ludger (ed.) (2012): Poor Leadership and Bad Governance. Chaltenham, UK: Edward Elgar.

HUNEEUS, Carlos (1985): La Unión de Centro Democrático y la transición a la democracia en España. Madrid: Centro de Investigaciones Sociológicas- Siglo XXI Editores.

HUNEEUS, Carlos (2003): Chile, un país dividido. La actualidad del pasado. Santiago: Catalonia.

HUNEEUS, Carlos (2014): La democracia semisoberana. Chile después de Pinochet. Santiago: Taurus.

HUNEEUS, Carlos (2016): El régimen de Pinochet. Santiago: Taurus.

HUNEEUS, Carlos (2017): "The quality of democracy: political legacies of economic modernization under authoritarian rule in Chile”, en: MOISÉS, José A. (ed.). Building Democracies. Challenges, Crisis and Responses to Rule of Law, Access to Justice and Political Representation. Rockville-MD: Global South Press, pp. 111-133.

HUNEEUS, Carlos (2020): “QQué le pasó a Chile el 18-o? ¿Hacia la Argentina del siglo XXI?”. Cuadernos 19, Fundación Manuel Giménez Abad, junio, pp. 136-168. Disponible en https://www.fundacionmgimenezabad.es/sites/default/files/Publicar/ publicaciones/documentos/cuadernos_19_junio_2020_o.pdf [Fecha de consulta: 6 de diciembre de 2020].

HUNEEUS, Carlos y COUSO, Javier (eds.) (2016): Eduardo Frei Montalva: un gobierno reformista. A 50 años de la "Revolución en Libertad". Santiago: Editorial Universitaria.

HUNEEUS, Carlos y AVENDAÑO, Octavio (2018). "Los partidos políticos y su debilitamiento", en Carlos HUNEEUS y Octavio AVENDAÑO (eds.). El sistema político de Chile. Santiago: Lom Ediciones, pp. 153-191. 
INGLEHART, Ronald (2016): "Inequality and Modernization. Why Equaliy is Likely to Make a Comeback”. Foreign Affairs Nº5, pp. 2-10.

IONESCU, Guita (1991): Leadership in an Interdependent World. Essex: Logmand.

JARA ROMÁN, Sergio (2018): Piñera y los leones de Sanhattn. Crónica del auge de la élite financiera chilena. Santiago: Planeta.

KELLERMAN, Barbara (2004): Bad Leadership: What It is, How It Happens, Why It Matters. Boston: Harvard Business School.

LANZARO, Jorge (compilador) (2003): Tipos de presidencialismo y coaliciones politica en América Latina. Buenos Aires: CLACSO.

LINZ, Juan J. (1994): "Presidential or Parliamentary Democracy: Does it Make a Difference?”. En LINZ, Juan y VALENZUELA, Arturo (eds.) The Failure of Presidential Democracy. Comparative Perspectives. Baltimore: The Johns Hopkins University Press, año 1, pp. 3-87.

LINZ, Juan y VALENZUELA, Arturo (eds.) (1994): The Failure of Presidential Democracy. Comparative Perspectives. Baltimore: The Johns Hopkins University Press.

LINZ, Juan J. y STEPAN, Alfred (1996): Problems of Democratic Transition and Consolidation. Baltimore: The John Hopkins University Press.

LUNA, Juan Pablo (2017): En vez del optimismo. Crisis de representación política en el Chile actual. Ciper-Catalonia.

LLANOS, Mariana y MARGHERITIS, Ana (2006): "Why Do Presidents Fail? Political Leadership and the Argentine Crisis, 1999-2001". Studies in International Comparative Development, año 40, Nº, pp. 77-103.

LLANOS, Mariana y LEIV, Marsteintredet (eds.) (2010): Presidential Breakdown in Latin America. Causes and Outcomes of Executive Instability in Developing Democracies. Londres: Palgrave MacMillan.

MAINWARING, Scott y SOBERG SHUGART, Matthew (1997): Presidentialism and democracy in Latin America. Cambrige: Cambridge University Press.

MARTÍNEZ, Christopher A. (2017a): “Sobreviviendo” la presidencia argentina, 19832001". Estudios Internacionales, $\mathrm{N}^{\circ}$ 186, pp. 91-118.

MARTÍNEZ, Christopher A. (2017b): "Presidential Survival in Latin America: Rethinking the Role of Democracy”. International Political Science Review No38, pp.4055 .

MARTÍNEZ, Christopher A. (2020): "Presidential Instability in Latin America: Why Institutionalised Parties Matter." Government and Opposition. doi:10.1017/ gov.2020.18. 
MAC-IVER, R. M. (1948): Causación social. México: Fondo de Cultura Económica.

MORGENSTERN, Scott y NACIF, Benito (ed.) (2002): Legislative Politics in Latin America. Cambridge: Cambridge University Press.

NAVARRO, Federico y TROMBEN, Carlos (2019): "Estamos en guerra contra un enemigo poderoso, implacable”: los discursos de Sebastián Piñera y la revuelta popular en Chile". Literatura y Lingüistica, No 40, pp. 295-324.

NEUSTADT, Richard E. (1960): Presidencial Power and the Modern Presidents. Nueva York:The Free Press.

NYE, Jr., Joseph S. (2008): The Powers to Lead. Oxford: Oxford University Press.

RUSTOW, Dankward A. (ed.) (1970): Philisophers and Kings. Studies in Leadership. Nueva York: Brazillier.

SHUGART, Matthew Soberg y CAREY, John M. (1992): Presidents and Assemblies. Constitutional Design and Electoral Dynamics. Cambridge: Cambridge University Press.

TROMBEN, Carlos (2016): Crónica secreta de la economia chilena. Santiago: Ediciones B Chile S.A.

VALENZUELA, Arturo (1985): "Orígenes y características del sistema de partidos políticos en Chile: proposición para un gobierno parlamentario". Estudios Públicos $\mathrm{N}^{\circ} 18$, pp. 88-154.

VIAL, Gonzalo (1986): Arturo Alessandri y los golpes militares (1920-1925. Historia de Chile (1891-1973). Santiago: Santillana del Pacífico.

WEBER, Max (1982): “La política como vocación”, en sus Escritos políticos. México: Folios Ediciones, II tomo (originalmente 1920). 
Anexo. La concentración de la riqueza en América Latina y en algunos países avazados.

\begin{tabular}{|c|c|c|c|c|}
\hline País & Año & $\mathbf{1 \%}$ & $\mathbf{0 , 1} \%$ & $\mathbf{0 , 0 1 \%}$ \\
\hline Chile & 2013 & $28,7 \%$ & $13,7 \%$ & $6,2 \%$ \\
\hline Brasil & 2015 & $28,3 \%$ & $13,7 \%$ & $6,5 \%$ \\
\hline Colombia & 2010 & $20,4 \%$ & $7,4 \%$ & $2,6 \%$ \\
\hline Estados Unidos & 2014 & $20,2 \%$ & $9,3 \%$ & $4,4 \%$ \\
\hline Argentina & 2004 & $16,8 \%$ & $7,02 \%$ & $2,49 \%$ \\
\hline Uruguay & 2012 & $14,0 \%$ & $4.60 \%$ & $1.50 \%$ \\
\hline Alemania & 2013 & $13,2 \%$ & $5,4 \%$ & $2 \%$ \\
\hline España & 2012 & $8,6 \%$ & $2,77 \%$ & $1,01 \%$ \\
\hline
\end{tabular}

Fuente: Elaboración propia con datos de Piketty. T., \& E. Sáez en "World Inequality Database", y de Piketty. T., \& E. Sáez. (2013). "Top Incomes and the Great Recession Recent", IMF Economic Review, vol. 61, no. 3, pp. 456-478, ambos de https://wid. world/.

Para Chile, Engel (2013) http://www2.latercera.com/voces/el-uno-por-ciento-chile-y-el-mundo/ y https://wid.world/country/chile/.

Para el caso de Brasil se utilizaron datos de Morgan, M., "Falling Inequality beneath Extreme and Persistent Concentration: New Evidence for Brazil Combining National Accounts, Surveys and Fiscal Data, 2001-2015", WID. world Working Paper, 2017/12. https://wid.world/country/brazil/.

Los datos de Colombia se consultaron en Alvaredo, F., Londoño Velez, J., "High incomes and personal taxation in a development economy. Colombia 1993-2010," CEQ working paper 12, 2013. https://wid.world/country/colombia/.

Para Estados Unidos se consultó a Piketty, T., Sáez, E., Zucman, G., "Distributional National Accounts: Methods and Estimates for the United States", WID. World Working Paper, 2016/3. https://wid.world/country/usa/.

Los datos de Argentina se consultaron en Alvaredo, F., "The Rich in Argentina over the Twentieth Century, Top Incomes: A Global Perspective”, OUP, 2010. https:// wid.world/country/argentina/.

Para Uruguay se utilizaron datos de Burdín, G., de Rosa, M., Vigorito A., "Uruguay Estimates of Top Income Shares 2009-2012", WID. World Technical Note, 2015/2. https://wid.world/country/uruguay/.

En el caso de Alemania se consultó a Bartels, C. “Top incomes in Germany, 18712013", WID. world Working Paper 2017/18. ; Bartels, C., Jenderny, K., "The Role of Capital Income for Top Incomes Shares in Germany", WID. world Working Paper, 2015/1. https://wid.world/country/germany/. 
Para España se utilizaron datos presentes en Alvaredo, F., Estévez Bauluz, L., "Spain: Estimates of Top Income Shares 2011-2012, and Revision for 2001-2010", WID. World Technical Note, 2014/4. https://wid.world/es/country/es-spain/.

(*) La información corresponde al último año de estudio de cada país consultado en 09/2018 y revisado por última vez en 06/2020. 